\title{
LPPLS Bubble Indicators over Two Centuries of the S\&P 500 Index
}

\author{
Qunzhi Zhang \\ ETH Zurich, Department of Management, Technology and Economics (D-MTEC) \\ Scheuchzerstrasse 7, CH-8092 Zurich, Switzerland \\ E-mail address: qzhang@ethz.ch
}

Didier Sornette*

\author{
ETH Zurich, Department of Management, Technology and Economics, ,Scheuchzerstrasse 7, \\ CH-8092 Zurich, Switzerland; Swiss Finance Institute, c/o University of Geneva, 40 blvd. Du \\ Pont d'Arve, CH-1211 Geneva 4, Switzerland \\ E-mail address: dsornette@ethz.ch \\ Mehmet Balcilar \\ Department of Economics, Eastern Mediterranean University, Famagusta, Turkish Republic of \\ Northern Cyprus, via Mersin 10, Turkey; Department of Economics, University of Pretoria, \\ Pretoria, 0002, South Africa; and IPAG Business School, Paris France \\ E-mail address: mehmet.balcilar@emu.edu.tr \\ Rangan Gupta \\ Department of Economics, University of Pretoria, Pretoria, 0002, South Africa \\ E-mail address: rangan.gupta@up.ac.za \\ Zeynel Abidin Ozdemir \\ Department of Economics, Gazi University, Besevler, 06500, Ankara, Turkey; and \\ Economic Research Forum (ERF), Cairo \\ E-mail address: zabidin@gazi.edu.tr \\ Hakan Yetkiner \\ Department of Economics, Izmir University of Economics, Balcova, 35330, Izmir, Turkey \\ E-mail address: Hakan.Yetkiner@ieu.edu.tr
}

\begin{abstract}
The aim of this paper is to present novel tests for the early causal diagnostic of positive and negative bubbles in the S\&P 500 index and the detection of End-of-Bubble signals with their corresponding confidence levels. We use monthly S\&P 500 data covering the period from August 1791 to August 2014. This study is the first work in the literature showing the possibility to develop reliable ex-ante diagnostics of the frequent regime shifts over two centuries of data. We show that the DS LPPLS (log-periodic power law singularity) approach successfully diagnoses positive and negative bubbles, constructs efficient End-of-Bubble signals for all of the well-documented bubbles, and obtains for the first time new statistical evidence of bubbles for some other events. We also compare the DS LPPLS method to the exponential curve fitting and the generalized sup ADF test approaches and find that DS LPPLS system is more accurate in identifying well-known bubble events, with significantly smaller numbers of false negatives and false positives.
\end{abstract}

Keywords: S\&P 500, LPPL method, stock market bubble, forecast, bubble indicators JEL classification: J16, O47, C32

\footnotetext{
${ }^{*}$ Corresponding author.
} 


\section{Introduction}

The US market capitalization of firms rose from \$2.8 trillion in the end of 1988 to $\$ 18.7$ trillion in the end of 2012 in current prices and hence increased 6.7 times in 15 years or $13.5 \%$ per year in average compounded growth. Correspondingly, \$1.8 trillion in the end of 1998 and $\$ 9.6$ trillion in the end of 2012 of corporate equities was held by households and non-profit organizations in the US. ${ }^{1}$ Given the level of penetration of the stock market investment in US, a boom or a bust in the market has widespread effects on US economy, beyond its effect on the wealth of households and the value of firms. Therefore, it is vital to diagnose booms and busts before they hit the stock market.

The S\&P 500 (S\&P500) is one of the most frequently used stock market index in gauging the US stock market performance. The S\&P price index, like many other assets, shows positive and negative bubbles in certain periods, which seems to contradict with the Efficient Market Hypothesis. Since Sornette et al. (1996), there is a growing research using critical points with log-periodic corrections, borrowed from statistical physics, in identifying bubbles. ${ }^{2}$ This methodology (later started to be called Johansen-Ledoit-Sornette (JLS) model or Log-Periodic Power Law Singularity (LPPLS) analysis) proposes that a bubble can emerge intrinsically out of the natural functioning of the market. A brief survey of this literature is as follows. ${ }^{3}$ To further test the methodology, Sornette and Johansen (1997) used the two largest historical crashes of the century, the October 1929 and October 1987 crashes, and showed that the methodology identifies the two crashes by analysis bubbles developing over an interval of 8 years prior to when they happened. Sornette and Johansen (1998) presented a simple hierarchical model of traders in stock markets, e.g., currency blocks at the highest level of the hierarchy, the countries at the next level, major banks

\footnotetext{
${ }^{1}$ See Balance Sheet of Households and Nonprofit Organizations (B.100) in Financial Accounts of the United States.

${ }^{2}$ See Sornette (1998) demonstrating the analogies between the quantification of risks in finance and insurance and the optimization of portfolios on one hand and statistical physics concepts and methods on the other.

${ }^{3}$ Extended and condensed reviews of the literature can be found in Sornette (2003a) and Sornette et al. (2013), respectively.
} 
and institutions within a country then, and so forth, all exhibiting herd behavior. Sornette and Johansen (1998) showed that this hierarchical organization was sufficient to produce log-periodic oscillations and that a systemic instability could lead to a crash. Sornette and Zhou (2006) presented a systematic algorithm, which was implemented on the Dow Jones Industrial Average index (DJIA) and on the Hong Kong Hang Seng composite index (HSI). The algorithm detected in advance significant drops or changes of regimes. Sornette et al. (2009) analyzed the 2006-2008 oil prices run-up by using several implementations of LPPLS methodology and evidenced that oil prices exhibited a bubble-like dynamics. ${ }^{4}$ Jiang et al. (2010) applied the LPPLS model to detect two bubbles and subsequent market crashes in two important indexes in the Chinese stock markets between May 2005 and July 2009, the Shanghai stock exchange composite index and the Shenzhen stock exchange component index and successfully predicted time windows for both crashes in advance. Johansen and Sornette (2010) presented a systematic analysis of drawdown outliers and showed that they are either preceded by a (super-exponential) power law price appreciation decorated by LPPLS signatures or by exogenous shocks. Yan et al. (2012), using the JLS model, developed an alarm index based on an advanced pattern recognition method with the aim of detecting bubbles and performed forecasts of market crashes and rebounds. Testing their methodology on ten major global equity markets, they showed quantitatively that their a alarm method performs much better than chance in forecasting market crashes and rebounds. Filimonov and Sornette (2013) proposed a revision of the LPPLS formulation convenient for more stable calibrations, by transforming it from a function of 3 linear and 4 nonlinear parameters into a representation with 4 linear and 3 nonlinear parameters. This transformation significantly decreases the complexity of the fitting procedure and improves its stability. In addition to this, they developed an additional subordination procedure that allows one to detect the critical time, the end of the bubble and the most probable time for a crash to occur. This further decreases the complexity of the search. Filimonov

${ }^{4}$ The simple LPPLS model (Sornette and Johansen, 2001), the second-order Weierstrass model (Zhou and Sornette, 2003) and the second-order Landau model (Sornette, 1997; Johansen and Sornette, 1999, 2000). 
and Sornette (2013) used the Shanghai Composite index (SSE) from January 2007 to March 2008 to test the modified LPPLS model. The research team at ETH Zurich further developed an LPPLS based bubble detection system, which is described Sornette et al. (2015) and Zhang et al. (2015). Three indicators used in this system are the Bubble Status (DS LPPLS Bubble Status), the End-ofBubble signal (DS LPPLS End-of-Bubble), and the confidence (DS LPPLS Confidence), which are also used in this study.

The aim of the present study is to identify positive and negative bubbles in S\&P500 since the first month of 1814, based on an initial estimation from August, 1791 to December, 2013, i.e., a rolling-window of 269 months. Sornette et al. (1996), Sornette (1998a), and Sornette and Johansen (1997, 1998) define a positive (negative) bubble an accelerating ascending (descending) log-price ending at some future critical time. That is, positive (negative) bubbles are not characterized by an exponential increase (decrease) of price but rather by a faster than exponential growth (decay) of price (Hüsler et al., 2013; Leiss et al., 2015). For this purpose, we use the log-periodic power law singularity (LPPLS) methodology, developed by Sornette et al. (1996), Sornette (1998a), and Sornette and Johansen $(1997,1998)$. The main motivation for using this methodology is to diagnose the bubbles ex-ante. We show that LPPL methodology is able to identify bubbles quite early, but the signals often do not stop immediately after the real bubbles fade. We undertake our analysis in two phases. In the first phase, the timeline of "DS LPPLS Bubble Status indicators" of the S\&P500 monthly data from January 1814 to August 2014 are derived. In the second phase, we derive the timeline of "DS LPPLS End-of-Bubble" signals and "DS LPPLS Confidence" indicators of the S\&P500 monthly data from January 1814 to August 2014. There are two times, 1842-1843 and 2002-2003, for which the End-of-Bubble signals of negative bubbles successfully predict the more than $30 \%$ rebounds, and our methods identify only those two clusters of End-of-Bubble signals of negative bubbles. The End-of-Bubble signals of positive bubbles, however, are able to predict a large fraction of the big drawdowns that develop in their future, with only two or three false alarms, 
resulting from the fact that sometimes the warnings come too early. There are 19 reported bear market, bubble, or crash periods ${ }^{5}$ in the history of US stock markets, which occurred during the sample period of the data used in this study. Some of these are well-known bubble periods, such as the Black Monday of 1987 and the Dot-com bubble of 2000. There is no clear evidence whether others were indeed crashes followed by a bubble period. Among these, the DS LPPLS End-of-Bubble and Confidence indicators correctly detect a change in regime (end of bubble) for 8 cases. Additionally, a change of regime is signaled quite earlier in a few other cases. The LPPL End-of-Bubble and Confidence indicators indicate bubble signals for the Panic of 1837, the Panic of 1869 (the Black Friday), the Panic of 1873, the Panic of 1884, the Wall Street Crash of 1929, the Black Monday of 1987, the Dot-com bubble of 2000, and the Subprime Financial Crises of 2007-2008. We further compare the results of the DS LPPLS model to the exponential curve fitting (EXCF) method of Watanabe et al. (2007a, 2007b) and to the generalized sup Augmented Dickey Fuller (GSADF) procedure of Phillips et al. (2015). The DS LPPLS system identifies more of the already documented and well-known bubbles compared to the two alternative methods. In addition to others, the EXCF and GSADF methods fail to identify two important bubble events, the Subprime Financial Crises of 20072008 and the Black Monday of 1987, respectively.

The rest of the paper is organized as follows. The next section presents a brief summary of the DS LPPLS methodology. Section 3 presents the findings. The final section concludes the paper.

\section{Methodology}

\footnotetext{
5 These 19 crash, bear market, or bubble events include Panic of 1837, Panic of 1857, Black Friday (24 Sep 1869), Panic of 1873, Panic of 1884, Panic of 1893, Panic of 1896, Panic of 1901, Panic of 1907, Wall Street Crash of 1929, Recession of 1937-38, Kennedy Slide of 1962, Black Monday (19 Oct 1987), Friday 13th mini-crash (13 Oct 1989), Early 1990s recession (July 1990), Dot-com bubble (10 March 2000), Stock market downturn of 2002, Subprime Mortgage Crisis of 2007-08, and Flash Crash of 2010.
} 
In this section, we recall the derivation of the log-periodic power law singularity (LPPLS) model. This presentation of the LPPLS is based on JLS (2000). JLS (2000) consider a risk neutral rational agent with rational expectations. This implies an asset price $p(t)$ following a martingale process. In market equilibrium, there is equality between asset price and its conditional expectation given all information available up to time $t$. This is a necessary condition for no arbitrage. Assume that $t_{c}$ is the unknown crash or end of bubble time, also called the critical time, with a probability density function $q(t)$, a cumulative distribution function $Q(t)$ and hazard rate $h(t)=q(t) /[1-Q(t)]$. As it is wellknown, the hazard rate gives the probability of a crash in the next time period given that it has not occurred yet. Let $k \in(0,1)$ denote the fixed percentage by which the price falls during a crash. Then the asset price dynamics can be described as follows:

$$
\begin{aligned}
& d p=\mu(t) p(t) d t-k p(t) d j+\sigma(t) p(t) d W \quad \Rightarrow \\
& E[d p]=\mu(t) p(t) d t-k p(t)[0+h(t) d t]=\mu(t) p(t) d t-k p(t) h(t) d t
\end{aligned}
$$

where $d W$ is the infinitesimal increment of the Wiener process with 0 mean and variance equal to $d t$. The term $d j$ denotes a discontinuous jump with $j=0$ before the crash and $j=1$ after the crash occurs. The equations of no arbitrage and rational expectations imply that $E[d p]=0$, yielding $\mu(t)=k h(t)$. Then the asset price dynamics before the crash occurs is given by the differential equation $E[d \ln p(t))=k h(t) d t$ with the following solution:

$$
E\left[\ln \left[\frac{p(t)}{p\left(t_{0}\right)}\right]\right]=\kappa \int_{t_{0}}^{t} h\left(t^{\prime}\right) d t^{\prime}
$$

As also remarked by Blanchard (1979), the higher the probability of a crash, the faster is the growth of the asset price in order to compensate investors for the increased risk of a crash. JLS (2000) further assumes that a power law describes the behavior of the variables close to a critical point and $\chi \approx A\left(\kappa_{c}-\kappa\right)^{-\gamma}$ describes susceptibility of the diverging system where $A$ is a 
positive constant and $\gamma$ is the positive critical exponent of susceptibility. See Seyrich and Sornette (2016) for a recent micro-foundation. The susceptibility quantifies the degree of sensitivity of a system to external perturbation. It is the probability that a group of agents will have the same state given externals influences in the network. In real financial markets, interacting investors are organized inside a hierarchical network, where people locally influence each other at many different levels. Therefore, JLS (2000) proposed a Hierarchical Diamond Lattice (HDL) in order to represent this aspect of reality in financial markets. In the structure of HDL after $n$ iterations there will be $N=(2 / 3)\left(2+4^{n}\right)$ agents and $L=4^{n}$ links among them. Derrida et al. (1983) solved a version of the HDL. It is similar to the rational imitation model in a random or regular network with one difference. Here the critical exponent of susceptibility, $\gamma$, can be a complex number. Then, the following expression gives the general expression of the power law singular behavior:

$$
\chi \approx A_{0}^{\prime}\left(\kappa_{c}-\kappa\right)^{-\gamma}+A_{1}^{\prime}\left(\kappa_{c}-\kappa\right)^{-\gamma} \cos \left[\omega \ln \left(\kappa_{c}-\kappa\right)+\psi\right]+\ldots
$$

where $A_{0}, A_{1}$ and $\omega$ are real numbers. The oscillations called "log-periodic" correct the pure power law singularity and reflects the underlying approximate discrete scale invariance of the financial price dynamics (Sornette, 1998b). The oscillations are periodic in $\ln \left(\kappa_{c}-\kappa\right)$ and $\omega$ is their angular log-frequency quantifying how the local period of the oscillations shrinks to zero as the critical time of crash is reached. $\kappa$ is a positive constant governing the tendency of imitation among agents, the order in which network increases with $\kappa . \kappa_{c}$ is the critical point determining the separation of different regimes. See Geraskin and Fantazzini (2013) for further discussion of the relationship between $\kappa$ and $\kappa_{c}$ and the assumption that $\kappa$ is locally linear in time. Within this mechanism, the behavior of the crash hazard rate is similar to that of susceptibility in the neighborhood of the critical crash point. We can then write the hazard rate as follows: 


$$
h(t) \approx B_{0}\left(t_{c}-t\right)^{-\alpha}+B_{1}\left(t_{c}-t\right)^{-\alpha} \cos \left[\omega \ln \left(t_{c}-t\right)+\psi^{\prime}\right]
$$

This expression shows that the hazard rate increases as the interactions among investors rise with time. Appling this hazard rate to the solution of asset price dynamics given by equation (2), we obtain the following equation which describes the evolution of the asset price before a crash, which is known as the Log Periodic Power Law singularity (LPPLS) formula:

$$
\ln [p(t)] \approx A+B\left(t_{c}-t\right)^{\beta}\left\{1+C \cos \left[\omega \ln \left(t_{c}-t\right)+\phi\right]\right.
$$

where $A=\ln \left(\mathrm{p}\left(t_{c}\right)\right)>0$ and $B<0$ for a positive bubble. $C$ quantifies the size of the log-periodic oscillations around the power law singular growth. $\beta$ is positive and less than unity. It quantifies the power law acceleration of asset prices. A positive $\beta$ ensures a finite asset price at the critical time $t_{c}$ of crash. The angular log-frequency of oscillations during the bubble is denoted by $\omega . \phi$ denotes the phase parameter, which is positive and less than $2 \pi$. These parameters are further described in Sornette and Johansen (2001) and Johansen (2003). The LPPLS formula (5) is the main equation describing the evolution of asset prices before a crash. This equation is given in various forms in several papers: Sornette (2003b), Lin et al. (2014), and Geraskin and Fantazzini (2013).

For both developed and emerging stock markets, Johansen et al. (1999), Johansen and Sornette (1999a), and Sornette and Johansen (2001) have documented that the most speculative bubbles have two common characteristics. First, a faster than exponential or super-exponential growth of the stock price during the bubble period, which ends when the bubble fades. This superexponential growth can be characterized by the power law singularity of the LPPLS model. Second, oscillations with an accelerating frequency that can be represented as approximately in geometrical proportional to the distance to the critical time $t_{c}$ (the most probable time for a regime change or end of bubble). 
The structure of the LPPLS model in equation (5) describes these features. The parameter $t_{c}$ is the most probable time for a change in the regime at which the growth rate changes, signifying a change in regime. The regime change may be the time of the crash, the burst of the bubble, or the fading of the bubble. Not all bubbles end with a crash and therefore the change in regime is not necessarily a crash. The regime change, however, will be a change from super-exponential growth to a lower growth and the end of the accelerating oscillations. The first component, $A+B\left(t_{c}-t\right)^{\beta}$, of the LPPLS model in equation (5) captures the super-exponential growth. Therefore, this component is the power law singular component. It is the component that embodies the positive feedback mechanism of a bubble development. For super-exponential growth, it is required that $0<\beta<1$, while positive and negative bubbles are characterized by $B<0$ and $B>0$, respectively. The sign requirements on $B$ arise from the condition that prices should rise during a positive bubble and fall during a negative bubble. Positivity of the prices requires $A>0$.

Replacing $t_{c}-t$ with $t-t_{c}$ in equation (5) gives a price dynamics that characterizes what is called an "anti-bubble" (Johansen and Sornette, 1999b; Zhou and Sornette, 2004; 2005). The second component, $C\left(t_{c}-t\right)^{\beta}$ describes the fact that the amplitude of the accelerating oscillations drop to zero at the critical time $t_{c}$ with additional requirements to guarantee a positive hazard rate (Bothmer and Meister, 2003). In the LPPLS model, the term $\omega \ln \left(t_{c}-t\right)$ models the fact that the local frequency of oscillations becomes infinite at the critical time $t_{c}$. It is in general required that $6 \leq \omega \leq 13$ so that the log-periodic oscillations to be neither too fast (fitting to the random component of the data), nor too slow (providing a contribution to the trend). Finally, $\phi$ in equation (5) is associated with a characteristic time units for the oscillations.

The LPPLS equation (5) has 3 linear parameters $(A, B, C)$ and 4 nonlinear parameters $\left(\beta, \omega, t_{c}, \phi\right)$. In order to simplify the estimation, usually 3 linear parameters $A, B, C$ are "slaved" in the fitting algorithm and estimated 
from the given values of the nonlinear parameters $\beta, \omega, t_{c}$, and $\phi$ (see, e.g., Johansen et al., 1999). A common method of estimation for the LPPLS equation (5) is the nonlinear least squares. However, minimization of nonlinear multivariate least squares functions is non-trivial due to presence of multiple local minima, where the well-studied algorithms, such as the steepest descent or the Newton's method, usually will get trapped. In order to overcome to complexity of the minimization, metaheuristic algorithms such as the taboo search or genetic algorithm is used to estimate the parameters of the LPPL model. Filimonov and Sornette (2013) proposed transforming the LLPLS equation (5) in order to reduce the number of nonlinear parameters from 4 to 3 at the expense of increasing the number of linear parameters from 3 to 4 . The transformation substantially reduces the complexity of the fitting procedure and improves its stability, allowing the simple algorithms, such as the GaussNewton algorithm, to be used efficiently. The transformed function is characterized by better smooth properties and in general by a single or a few minima. This study also uses the procedure of Filimonov and Sornette (2013) in order to estimate the parameters of the LPPLS model.

\section{Data and Empirical Results}

\subsection{The DS LPPLS bubble identification}

We collected monthly data on the Standard and Poor's S\&P 500 (S\&P500) stock market index from August 1791 through August 2014 for 2677 observations. Data come from the Global Financial Database. The LPPLS model is estimated with a 269 month rolling window.

We define two targets for our investigation: positive bubbles and negative bubbles. A positive bubble is an ascending accelerating (transient super-exponential) price ending at some future critical time $t_{c}$. A negative bubble is the mirror image of a positive bubble under a flip of the vertical price axis, and thus characterizes an accelerating descending price ending at some 
future critical $t_{c}$, which may be followed by a rebound or rally. To illustrate why the concept of negative bubble is useful, consider the case when the CHF in Euro is exhibiting a positive bubble. Then, by construction, the Euro in CHF follows a negative bubble. The notion of a positive bubble (or bubble in the standard definition) assumes that the numeraire (the value of reference) in which the price is expressed has no ambiguity. Usually, it is taken as being the US dollar. However, this does not need to be the case and stressing the value of reference provides novel insights. Negative bubbles are interesting for the study of arbitrary pairs of assets where one asset is expressed in units of the other. Another way to express the same thing is to consider a self-financing portfolio that is long the first asset and short the second asset. For instance, the value of the S\&P500 in US dollars is that of a portfolio long in the US market and short in US dollars. A negative bubble found in the S\&P500 in US\$ means that the S\&P500 is exhibiting an accelerating depreciation with respect to the US\$. A positive bubble in the S\&P500 in US\$ can also be interpreted as the US\$ depreciating with respect to the basket of assets in the S\&P500 portfolio, in other words the existence of a kind of inflation in the US currency (see Zhou and Sornette, 2005, for a vivid illustration of this phenomenon).

Figures 1-5 show our bubble indicators for the S\&P500 monthly data. All the analyses are causal, i.e. make diagnostic of the presence of a potential bubble at a given time $t$ using only data before a present running "present" time $t$, i.e. before and until the time $t_{c}$. In the figures, we tag the periods of positive (resp. negative) bubbles by the red (resp. green) color, while blank (white) indicates the absence of bubbles, according to our methodology. The red marks diagnose positive bubbles, associated with upward accelerating prices, which are susceptible to regime change in the form of crashes or volatile sideway plateaus. The green marks diagnose negative bubbles, associated with downward accelerating prices, which are susceptible to change of regimes in the form of rallies or volatile sideway plateaus. One can observe that bubbles are identified quite early, but the signals often do not stop immediately as the real bubbles fade. 
Figures 1-5 show the timeline of "DS LPPLS Bubble Status indicators" of the S\&P500 monthly data from January 1814 to August 2014. A DS LPPLS Bubble Status indicator at any time $t$ is constructed by looking for bubble patterns in the 269 months before $t_{c}$ by calibrating the log-price time series with the LPPLS model. If a portion of the 269 historic data points can be fitted by the LPPLS model better than by an average exponential growth model, the status at $t_{c}$ is marked as either a positive bubble or a negative bubble, according to the average positive versus negative trending price in the calibration window, with red color or green color, respectively. The status of those periods that remain blank (white) is no bubble.

- Insert Figure 1-5 here-

The DS LPPLS Bubble Status indicators in Figures 1-5 show the possible periods where super-exponential growth is observed. The marked periods do not all correspond to bubbles or negative bubbles. The DS LPPLS Bubble Status indicators mark existence of possible bubbles for the well-known 19 bear market, bubble, or crash periods ${ }^{7}$ in the history of US stock markets, which our study period covers. Although some of these events are classified as known bubbles, there is no clear evidence on the status of the others. Among the period outlined particularly by the DS LPPLS Bubble Status indicators in Figures 1-5, the following one are known bubble events: the Black Friday of 1869, the Wall Stress Crash of 1929, the Black Monday of 1987, the Dot-com bubble of 2000, and the Subprime Mortgage Crisis of 2007-08 are. These events are listed in Table 1 along with some others that are classified as bubble. There are some other periods where the DS LPPLS Bubble Status indicates the possible existence of bubbles. We next examine the existence of bubbles in these periods using robust indicators.

Table 1. The Events Classified as Bubble by the DS LPPLS System

\begin{tabular}{|l|l|l|}
\hline The Event & Description & Change in the S\&P500
\end{tabular}

${ }^{7}$ See footnote 5 above. 


\begin{tabular}{|c|c|c|}
\hline & & $\begin{array}{l}\text { and DS LPPL Confidence } \\
\text { Value }\end{array}$ \\
\hline $\begin{array}{l}\text { The Panic of } \\
1837^{8} \text { and the } \\
\text { subsequent } \\
\text { Six Year } \\
(1837-1843) \\
\text { Depression }\end{array}$ & $\begin{array}{l}\text { The crisis was due to a period of sharply } \\
\text { rising prices of land, cotton, and slaves from } \\
\text { mid- } 1834 \text { to mid- } 1836 \text {. It was followed by a } \\
\text { sharp decline in these prices. The panic had } \\
\text { both domestic and foreign origins, such as } \\
\text { credit constraints imposed by the UK. The } \\
\text { subsequent recession made profits, prices, } \\
\text { and wages to go down and unemployment to } \\
\text { raise. }\end{array}$ & $\begin{array}{l}\text { The S\&P index started to } \\
\text { surge in } 1830 \text { and peaked to } \\
3.6 \text { in mid- } 1835 \text {. After then, } \\
\text { the bubble burst and the } \\
\text { index fell to } 2.25 \text { in } 1837 \\
\text { and made a trough in } 1843 \\
\text { at } 1.6 \text {. The cumulative } \\
\text { decline from June } 1835 \text { to } \\
\text { March } 1835 \text { exceeded } 50 \% \text {. } \\
\text { DS LPPLS Confidence } \\
\text { value: } 0.004\end{array}$ \\
\hline $\begin{array}{l}\text { Black Friday, } \\
\text { 24 Sep } 1869\end{array}$ & $\begin{array}{l}\text { The United States Government issued a } \\
\text { large amount of government debt, which } \\
\text { were fiat greenbacks not backed by gold, } \\
\text { during the reconstruction era following the } \\
\text { Civil War. A group of speculators attempted } \\
\text { to benefit from this. On September } 20,1869 \text {, } \\
\text { the speculators started hoarding gold and } \\
\text { caused the Black Friday. }\end{array}$ & $\begin{array}{l}\text { The S\&P index has risen } \\
\text { more than } 70 \% \text { from April } \\
1868 \text { to September } 1869 \text {. } \\
\text { Following the Black Friday, } \\
\text { the index fell by } 7 \% \text { in } \\
\text { September } 1869 . \text { DS LPPL } \\
\text { Confidence value: } 0.001\end{array}$ \\
\hline $\begin{array}{l}\text { The Panic of } \\
1873^{9}\end{array}$ & $\begin{array}{l}\text { The U.S. economy experienced an economic } \\
\text { expansion between 1866-1873 due to heavy } \\
\text { investment in transportation and protective } \\
\text { tariffs. However, overproduction against a } \\
\text { declining market, deflation, and the } \\
\text { depression in Europe triggered a depression } \\
\text { that lasted from } 1873 \text { until } 1879 \text {. It is also } \\
\text { called long depression or great depression. }\end{array}$ & $\begin{array}{l}\text { The S\&P index started to } \\
\text { rise in } 1866 \text {, and was a } \\
\text { positive bubble between } \\
1869-1873 \text {. Thereafter, the } \\
\text { index started to fall until } \\
1879 \text {, following a negative } \\
\text { bubble. DS LPPL } \\
\text { Confidence value: } 0.008\end{array}$ \\
\hline Panic of 1884 & $\begin{array}{l}\text { The panic occurred during the Recession of } \\
1882-85 \text {. The panic was caused by two bank } \\
\text { failures having ripple effect across Wall } \\
\text { Street causing many firms to fail. } \\
\text { Speculative bonds and over extension of } \\
\text { credit to fund the infrastructure construction, } \\
\text { which caused a panic in 1882, also } \\
\text { contributed to the panic of } 1884 \text {. }\end{array}$ & $\begin{array}{l}\text { The S\&P index fell from } \\
5.34 \text { in Dec } 1883 \text { to } 4.23 \text { by } \\
\text { the end of Dec } 1884 \text { with a } \\
\text { cumulative decline of } \\
25.26 \% \text { DS LPPL } \\
\text { Confidence value: } 0.002\end{array}$ \\
\hline $\begin{array}{l}\text { The Great } \\
\text { Depression } \\
\text { (The Wall } \\
\text { Street Crash } \\
\text { of 1929) }\end{array}$ & $\begin{array}{l}\text { Speculation in stock market, production } \\
\text { and/or sales fall in several manufacturing } \\
\text { industries, high debts due to easy crediting, } \\
\text { falling prices in some agricultural products } \\
\text { and heavy emigration from rural to urban are } \\
\text { listed as the causes of the great depression. }\end{array}$ & $\begin{array}{l}\text { The S\&P index started to } \\
\text { surge in mid-1921 from } 5.4 \\
\text { and peaked at } 32 \text { in } 1929 . \\
\text { Thereafter, the bubble burst } \\
\text { and the index made a trough } \\
\text { in mid-1932 by falling even } \\
\text { below 5. DS LPPL } \\
\text { Confidence value: } 0.014\end{array}$ \\
\hline $\begin{array}{l}\text { Black } \\
\text { Monday, } \\
\text { Oct } 1987\end{array}$ & $\begin{array}{l}\text { Black Monday refers to Monday, October } \\
19,1987 \text {, the day the major stock markets } \\
\text { around the world crashed, with huge losses } \\
\text { in a very short time. It started in Hong Kong } \\
\text { and spread west to Europe, and later to the } \\
\text { United States after other major markets of } \\
\text { Europe declined significantly. }\end{array}$ & $\begin{array}{l}\text { The S\&P index fell exactly } \\
70 \text { points from September } \\
1987 \text { to October } 1987 \\
(24.54 \% \text { decline). The } \\
\text { cumulative decline in the } \\
\text { S\&P index exceeded } 33 \% \\
\text { by the end of November }\end{array}$ \\
\hline
\end{tabular}

\footnotetext{
${ }^{8}$ See Rousseau (2002).

${ }^{9}$ See Barreyre (2011), Lubetkin (2006) and Coppock (1961) on the causes.

${ }^{10}$ See Friedman and Schwarz (1963) for monetary-related, Bernanke (1983) for credit related, and Temin (1989) and Bernanke and James (1991) for gold-standard causes of the depression.
} 


\begin{tabular}{|c|c|c|}
\hline & & $\begin{array}{l}\text { 1987. DS LPPL Confidence } \\
\text { value: } 0.001\end{array}$ \\
\hline $\begin{array}{l}\text { Dot-com } \\
\text { bubble, } 10 \\
\text { March } 2000\end{array}$ & $\begin{array}{l}\text { Based on confidence on technological } \\
\text { advancements, inventors overlooked } \\
\text { traditional metrics and stock prices of } \\
\text { Internet-based companies experienced fast } \\
\text { growth during the period of 1997-2000. } \\
\text { Companies could raise their stock prices by } \\
\text { simply adding an "e-" prefix to their name or } \\
\text { a ".com" to the end. The bubble collapsed } \\
\text { during 1999-2001 and many companies } \\
\text { completely failed. }\end{array}$ & $\begin{array}{l}\text { When the Dot-com bubble } \\
\text { ended, the share prices fell } \\
\text { dramatically. The crash } \\
\text { following the end of bubble } \\
\text { caused } \$ 5 \text { trillion loss in the } \\
\text { market value of companies } \\
\text { from March } 2000 \text { to } \\
\text { October } 2002 \text {. The S\&P } \\
500 \text { fell from } 1498.58 \text { in } \\
\text { March } 2000 \text { to } 815.28 \text { by } \\
\text { October } 2002 \text {, a } 60.85 \% \\
\text { decline. DS LPPL } \\
\text { Confidence value: } 0.018\end{array}$ \\
\hline $\begin{array}{l}\text { Subprime } \\
\text { Mortgage } \\
\text { Crisis } \\
2007-08\end{array}$ & $\begin{array}{l}\text { The financial crisis of } 2007-08 \text { was } \\
\text { triggered by the bursting of the housing } \\
\text { bubble in the US, which peaked in mid } \\
2006 \text {. Following, the end of the bubble the } \\
\text { default rates on subprime and adjustable-rate } \\
\text { mortgages (ARM) increased quickly. Thus, } \\
\text { the crisis is also called the Subprime } \\
\text { Mortgage Crises. The financial crisis of } \\
2007-08 \text { is considered to be the worst crisis } \\
\text { since the Great Depression. The crisis later } \\
\text { on led to the } 2008-2012 \text { global recession } \\
\text { and also contributed to the European } \\
\text { sovereign-debt crisis. The total cost of the } \\
\text { crisis is estimated around } \$ 10 \text { trillion to } \$ 12 \\
\text { trillion, corresponding to the drop in value of } \\
\text { world stock markets and around } \$ 5.7 \text { trillion } \\
\text { to } \$ 12.8 \text { trillion of loss in US output. }\end{array}$ & $\begin{array}{l}\text { The U.S. stock market } \\
\text { peaked in October } 2007 \\
\text { with the S\&P index } \\
\text { reaching 1549.38. The } \\
\text { market then entered a } \\
\text { prolonged decline and by } \\
\text { March } 2009 \text { the S\&P index } \\
\text { fell to } 735.39 \text { a } 52.54 \% \\
\text { fall. DS LPPL Confidence } \\
\text { value: } 0.001 \text {. }\end{array}$ \\
\hline
\end{tabular}

For the robust detection of bubbles, we use the End-of-Bubble signal (DS LPPLS End-of-Bubble) and the confidence (DS LPPLS Confidence) indicators, which are based on the bubble detection system described in Sornette et al., 2015, and Zhang et al., 2015.

The DS LPPLS End-of-Bubble signals are constructed with 269 historic monthly data points. At any time t, we fit the LPPLS model with the historic data and check the quality of the calibrations. A fit must pass a strict Lomb logperiodic test (Zhou and Sornette, 2002), unit-root test of the residuals (Lin and Sornette, 2013), and other criteria explained and justified in (Johansen and Sornette, 2010; Sornette et al., 2013). Moreover, we generate 3000 
bootstrapping samples by shuffling the residuals of the LPPLS fit, and check the fraction of the samples that can pass the same strict tests, which gives the value of the DS LPPLS Confidence indicator.

A DS LPPLS End-of-Bubble signal predicts that a bubble, either a positive bubble or a negative bubble, is going to end. The corresponding DS LPPLS Confidence indicator indicates the confidence level of the End-ofBubble signal. A higher value of a DS LPPLS Confidence indicator means that the corresponding End-of-Bubble signal is more reliable. End-of-Bubble signals of negative bubbles have negative DS LPPLS Confidence indicators. The DS LPPLS Confidence indicator robustly marks bubbles by measuring the sensitivity of the observed bubble pattern to the chosen starting time. If the pattern exists only in a few of the analyzed windows, the value of the DS LPPLS Confidence indicator will be close to zero. A DS LPPLS Confidence value close to one means that the bubble pattern shows almost no sensitivity to the choice of the data window. A very low value indicates risk of over-fitting since the signal is only observed in one or two specific windows. In this case, the result needs to be considered with care.

Figures 6-10 show the timeline of "DS LPPLS End-of-Bubble" signals and "DS LPPLS Confidence" indicators of the S\&P500 monthly data from January 1814 to August 2014. The purple shades in the upper graphs depict the drawdowns of the S\&P500 monthly data. ${ }^{11}$ There are two times, 1842-1843 and 2002-2003, for which the End-of-Bubble signals of negative bubbles successfully predict more than $30 \%$ rebounds, and our methods identify only those two clusters of End-of-Bubble signals of negative bubbles. The End-ofBubble signals of positive bubbles, however, are able to predict a large fraction

\footnotetext{
11 Johansen and Sornette $(1998,2001)$ developed a methodology to characterize drawdowns (drawups) robustly. Drawdowns (drawups) were simply defined as a continuous decrease (increase) in the value of the price, while allowing for small noise decorating the main trend. A drawdown (drawup) is terminated by a sufficiently large increase (decrease) in the price. Drawdowns (drawups) are thus robust cumulative losses (gains) from the last local maximum (minimum) to the next minimum (maximum).
} 
of the big drawdowns that develop in their future, with only two or three false alarms, resulting from the fact that sometimes the warnings come too early.

-Insert Figure 6-10 here-

The DS LPPLS End-of-Bubble and Confidence indicators accurately signal a change in regime (end of bubble) for 8 cases. All these are positive bubble cases. Additionally, the DS LPPLS End-of-Bubble and Confidence indicators indicate two negative bubbles. The positive bubbles signals correspond to following events: the Panic of 1837, the Panic of 1869 (the Black Friday), the Panic of 1873, the Panic of 1884, the Wall Street Crash of 1929, the Black Monday of 1987, the Dot-com bubble of 2000, and the Subprime Financial Crises of 2007-2008. Although other events have been welldocumented as bubbles before and have been studied using bubble detection methodologies, to the best of our knowledge, the evidence for bubble presented here for the Panic of 1837, the Panic of 1873, and the Panic of 1884 is novel. Therefore, our present study presents for the first time solid statistical evidence of bubbles for these cases. The description of these events and values of the DS LPPLS Confidence are given in Table 1. The highest three values of the DS LPPLS Confidence are estimated for the Dot-com bubble of 2000 (0.018), the Crash of 1929 (0.014), and the Panic of 1873 (0.008). Thus, the bubble confidence for the Panic of 1873 is considerably high. The DS LPPLS Confidence estimates are around 0.001 for the Black Friday of 1869, the Black Monday of 1987, and the Subprime Mortgage Crises of 2007-08. The DS LPPLS Confidence estimates are 0.002 and 0.004, respectively, for the Panic of 1837 and the Panic of 1884.

In most cases, the DS LPPLS Confidence estimates give bubble signals quite early before the end of the bubble period. The Panic of 1837 is signaled as early as 1833 , the Panic of 1884 as early as $1881-82$, the Crash of 1929 as early as 1927, and the Black Monday of 1987 as early as 1986 . However, the signal comes relatively late and weak for the Subprime Mortgage Crises of 2007-08. 
Two negative bubbles in 1842-1843 and 2002-2003 correspond to the Six Year Recession following the Panic of 1837 and Dot-com bubble of 2000, respectively. Therefore, the negative bubbles also corresponds to known welldocumented events.. There are, however, three bubble signals in 1903, 1946, 1955 for which there are no recorded events for these periods. The DS LPPLS Confidence value for 1955 has considerable high value of 0.011 relative to the other values observed. But one can observe clear change of regimes following the peak of these signals, suggesting value for mitigating market risks when using such indicators.

\subsection{Comparison with other methods}

In this section, we use two additional bubble identification methods in order to compare the results obtained from the DS LPPLS methodology. In this way, we can both compare the results and do a robustness check by using these alternative methods. Two methods we use for confirmatory and comparative analysis are the exponential curve fitting (EXCF) method of Watanabe et al. (2007a, 2007b) and the generalized sup augmented Dickey Fuller (GSADF) procedure of Phillips et al. (2015).

The EXCF is based on the idea that an exponential growth curve fits better than a linear model to bubble periods. The EXCF method determines a data based window size to date-stamp the bubbles and crashes automatically. The window size is determined such that exponential growth would not be observed when an exponential curve is fitted to the data covering a sample size larger than this minimum window size. Balcilar et al. (2014) and Deviren et al. (2014) use the EXCF method to identify bubbles in exchange rates and oil prices. The EXCF method is based on fitting the following exponential curve:

$$
p(t)-p(t-1)=\left(\omega_{1}\left(i ; T_{i}\right)-1\right)\left[p(t-1)-p_{0}\left(i ; T_{i}\right)\right]+f(t)
$$


where $p(t)$ is the price at time $t, \omega_{1}\left(i ; T_{i}\right)$ is the parameter that characterize the exponential growth behaviors in the $i$-th period of length $T_{i}$ (window size or time scale), and $f(t)$ is the error term. The case $\omega_{1}\left(i ; T_{i}\right)=1$ characterizes the random walk behavior and in this case $p_{0}\left(i ; T_{i}\right)$ does not have any specific role. For $\omega_{1}\left(i ; T_{i}\right)>1$, we have either exponentially increasing (bubble) or decreasing (crash) price behavior and $P_{0}\left(i ; T_{i}\right)$ gives the base line of the exponential divergence. The case $\omega_{1}\left(i ; T_{i}\right)<1$ characterizes prices that are convergent to $p_{0}\left(i ; T_{i}\right)$

In order to identify the bubble periods, the parameters $\omega_{1}\left(i ; T_{i}\right)$ and $p_{0}\left(i ; T_{i}\right)$ are uniquely estimated from the past $T_{i}$ data points by minimizing the root mean square error. In order to determine the window size $T_{i}$, we first fit an autoregressive model of order $4, \mathrm{AR}(4)$, to the monthly S\&P500 data. ${ }^{12}$ Then, we simulate synthetic price data from the fitted AR(4) by changing the window size from 20 to 400 . The value for $T_{i}$ is estimated as the minimum window size for which $\omega_{1}\left(i ; T_{i}\right) \leq 1$ always holds. With 2000 Monte Carlo simulations, we find that a window size of 100 is sufficient for the monthly S\&P500 data.

Once the minimum window size is determined, a rolling estimation procedure is used to determine the bubble periods. ${ }^{13}$ The procedure involves the following steps: (i): $\omega_{1}\left(i ; T_{i}\right)$ and $p_{0}\left(i ; T_{i}\right)$ are estimated by fitting equation (6) over the past $T_{i}$ steps, and if $\omega_{1}\left(i ; T_{i}\right)>1$, all time steps in the observing box of

\footnotetext{
${ }^{12}$ The order of the AR model is determined by the Bayesian Information Criterion (BIC).

${ }^{13}$ The rolling estimation of the parameter $\omega_{1}\left(i ; T_{i}\right)$ does not assume any parameter stability. This approach, given the optimal minimum window size, tracks the changes in $\omega_{1}\left(i ; T_{i}\right)$.
} 
size $T_{i}$ steps are assigned as exponentially divergent; and if $\omega_{1}\left(i ; T_{i}\right) \leq 1$ only the latest time step in the box is assigned as convergent; (ii) the box is shifted by one step and (i) is repeated; and (iii) after all periods are assigned a divergent or convergent status, neighboring divergent time steps are connected.

As the second method for confirmatory analysis, we make use the GSADF test procedure of Phillips et al., (2015). The GSADF is a recursive right-tailed unit root testing procedure that allows the identification of multiple periods of price explosiveness. Here, following the suggestions of Phillips et al., (2015), we use a window-size of 36 . This method uses a flexible moving sample test procedure to consistently and efficiently detect and date-stamp periods where a price series displays a root exceeding unity. The GASDF procedure is implemented by testing a unit root against a right sided alternative using a fraction $r_{w}$ of the sample, or a window size of $T_{w}=\left[r_{w} T\right]$, where $[\cdot]$ means the integer part. Then, a backward sup ADF test is used with a varying window size $r_{w}=r_{2}-r_{0}$, where the end point of the subsample remains fixed at a fraction $r_{2}$ of the entire sample, with the window size expanding from an initial fraction $r_{0}$ to $r_{2}$, and the sup of all such backward ADF tests are taken. In the GASDF test, the backward sup ADF is repeatedly implemented for each $r_{2} \in\left[r_{0}, 1\right]$ and sup of all such tests gives the final test value. Phillips et al. (2013) show that the GSADF test has efficient bubble detection capabilities even in the presence of multiple bubble episodes.

The bubble periods identified by the EXCF method and the GSADF test are given in Table 2. We first comment on the results from the EXCF model. The EXCF procedure identifies 14 bubble periods over the whole sample period. Among the 14 bubble periods, five corresponds to historically known and documented events as bubbles or crashes. These include the Panic of 1857, the Panic of 1901, the Wall Street Crash of 1929, the Black Monday of 1987, and the Dot-com bubble of 2000 . The EXCF method also gives a very early signal 
(two years ahead) for the Panic of 1837. According to the results summarized in Table 1, the EXCF method has eight false signals in total.

The list of bubble periods identified by the GSADF test is also given in Table 2. The GSADF test identifies 10 bubble periods, five of these corresponding to known and documented events, one as an early signal (for the panic of 1837 as early as 1835), and four false signals. The GASDF correctly identifies the Panic of 1857, the Wall Street Crash of 1929, the Dot-com bubble of 2000, the stock market downturn of 2002, and the Subprime Financial Crises of 2007-2008.

Table 2. The Periods Determined as Bubbles by the Exponential Model and the GSADF Test

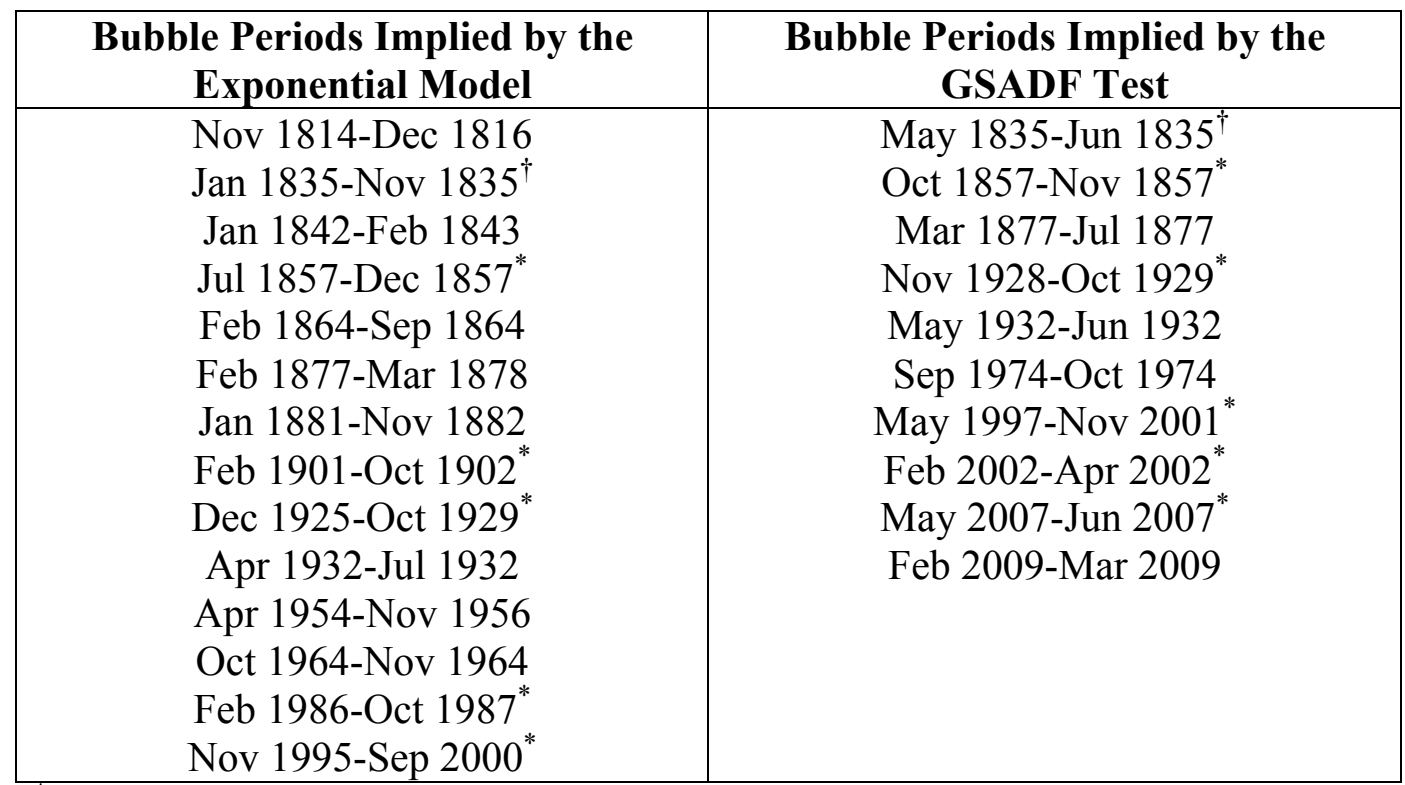

${ }^{*}$ Periods corresponding to known and documented historical bubbles or crashes.

${ }^{\dagger}$ Periods that precede to known and documented historical bubbles or crashes.

- Insert Figure 11-12 here-

When we compare the results of the EXCF model and of the GSADF test with the results of the DS LPPLS system, both the DS LPPLS and EXCF methods identify the same five bubbles while five bubbles are also jointly 
identified by both the DS LPPLS system and the GSADF test. Four bubbles, the Panic of 1837, the Panic of 1857, the Wall Street Crash of 1929, and the Dotcom bubble of 2000, are identified jointly by all three methods. Among the important historical events, the GSADF test fails to identify the Black Monday of 1987 while the EXCF method fails to identify the Subprime Financial Crises of 2007-2008. In sum, among the eight bubbles identified by the DS LPPLS system, the six events are also identified as bubbles by the EXCF and GSADF methods. Four of these six bubbles are identified by both the EXCF and GSADF methods, while each method additionally identifies one bubble period that are also identified as bubble by the DS LPPL system. We also note that the EXCF and GSADF methods cannot identify negative bubbles. The DS LPPLS system also identifies previously unclassified bubble regimes, which are clearly associated with significant changes of regimes, providing additional value for a global riks management perspective. Overall, the DS LPPLS system accurately identifies more of the historically events that are known as bubbles and has fever (or no) false signals (if one recognizes the value of the regime-switching identification). Among the three methods, the EXCF seem to give more frequent false bubble signals while the GSADF method diagnoses fewer bubbles than really exist.

\section{Conclusion}

In this study, we apply the LPPLS methodology introduced by Sornette et al. (1996) and Sornette and Johansen (1997, 1998), on monthly S\&P500 stock prices in order to identify bubbles and crashes in the US stock market using two centuries of data from 1814 to 2014. The distinguishing feature of this study from the previous studies is that this paper is the first of its kind that examines the existence of bubbles in the US stock prices using two hundreds years of monthly data with an advanced bubble detection methodology based on the LPPLS model. We found eight periods of positive bubbles in the S\&P500 and two periods of negative bubbles in the period from January 1814 to August 2014. Our analyses showed that the S\&P500 experienced positive bubbles in the 
following eight periods: the Panic of 1837, the Panic of 1869 (the Black Friday), the Panic of 1873, the Panic of 1884, the Wall Street Crash of 1929, the Black Monday of 1987, the Dot-com bubble of 2000, and the Subprime Financial Crises of 2007-2008. We showed that each of these bubble periods correspond to well-known and well-documented historical events, implying that the detection algorithm indeed accurately detect the bubbles. To the best of our knowledge, three of the bubble periods, the Panic of 1837, the Panic of 1873, and the Panic of 1884, that our methodology detects correspond to well-known events, but not studied in the literature using bubble detection methodologies. Two negative bubbles detected by our methodology do also correspond to known events. Thus the bubble indicators for these events are also correct signals.

Our study shows that, among the 19 events documented as bear market, crash, or the bubble in the history of the US stock market between 1814 and 2014, only eight events can be classified as positive bubbles with positive feedback mechanism. Additionally two events are classified as negative bubbles. These bubbles and crashes in the stock market, triggered by various reasons, all developed a positive (or negative in two cases) feedback mechanism, a self-perpetuating pattern of investment behavior. The positive (negative) feedback mechanism translates into super-exponential growth (decline) in stock prices. However, not all stock market crashed or crises are caused by internal bubble mechanisms with positive (negative) feedback mechanism. Some of these events are not preceded by faster than exponential price growths (declines) and the crashes are caused by various economic and political events, such as the recessions, panics, wars, end external influences.

We performed a confirmatory and comparative analysis using two alternative methods. Combined together, the EXCF and the GSADF methods do also identify six of the eight periods as bubbles, which were classified as bubbles by the DS LPPLS system. Both the EXCF and the GSADF methods fail to identify two well-known and well-documented bubbles. The Black Monday 
of 1987 and the Subprime Financial Crises of 2007-2008 are not identified as bubbles by the GSADF and EXCF methods, respectively. We also find that the GSADF method tends to signal fewer bubbles than the other two methods, while the EXCF method has the tendency to falsely detect too may bubbles. Both the GSADF and the EXCF methods do not identify negative bubbles and give higher number of false signals compared to the DS LPPLS method.

Our study shows that, with frequently occurring influential events in the last two centuries of the history of the US stock market, regime shifts, and change of regimes are the "norm" rather than the exception. The actors and policy makers should well be aware that that these regime shifts and change of regimes are likely to occur more frequently in the future (Sornette and Cauwels, 2014; 2015). Based on robust statistical evidence and a two hundreds years long monthly time series data, our study highlights that financial markets exhibit transitions between phases of growth, exuberance and crises (Lera and Sornette, 2015). Not all but most crises are endogenous and are the consequence of procyclical positive or negative feedbacks that eventually burst (Johansen and Sornette, 2010). Our study also shows that it possible to detect crashes ahead of time and reduce the welfare loss arising from these. The study underlines the importance a dynamical time at risk management (Kovalenko and Sornette, 2013) and its possibility, based on a sound monitoring system and scenario analysis that is capable of recognizing the ubiquitous of positive and negative feedbacks. 


\section{References}

Balcilar, M, Ozdemir, Z., and Yetkiner, I. 2014. Are there really bubbles in oil prices? Physica A 416, p. 631-638.

Barreyre, N. 2011. The Politics of Economic Crises: The Panic of 1873, the End of Reconstruction, and the Realignment of American Politics. The Journal of the Gilded Age and Progressive Era 10, 403-423.

Bernanke, B.S. 1983. Non-Monetary Effects of the Financial Crisis in the Propagation of the Great Depression. The American Economic Review 73, 257-276.

Bernanke, B.S., James, H. 1991. The Gold Standard, Deflation, and Financial Crisis in the Great Depression: An International Comparison. In: R. Glenn Hubbard, Ed., Financial Markets and Financial Crises, 33-68, Chicago \& New York: University of Chicago Press.

Blanchard, O.J. 1979. Speculative bubbles, crashes and rational expectations. Economics Letters 3, 387-389.

Bothmer, H.C.G. and Meister, C., 2003. Predicting critical crashes? A new restriction for the free variables. Physica A 320, 320, 539-547.

Coppock, D. J. 1961. The Causes of the Great Depression, 1873-96. The Manchester School 29, 205-32.

Derrida, B., De Seze, L., Itzykson, C. 1983. Fractal structure of zeros in hierarchical models. Journal of Statistical Physics 33, 559-569.

Deviren, B, Kocakaplan, Y., Keskin, M., Balcılar, M., Özdemir, Z.A., Ersoy, E. 2014. Analysis of bubbles and crashes in the TRY/USD, TRY/EUR, TRY/JPY and TRY/CHF exchange rate within the scope of econophysics. Physica A 410, 414-420.

Filimonov, V., Sornette, D. 2013. A stable and robust calibration scheme of the log-periodic power law model, Physica A 392, 3698-3707.

Friedman, M., Schwartz, A. J. 1963. Monetary History of the United States 1867-1960. Princeton: Princeton University Press.

Geraskin, P., Fantazzini, D. 2013. Everything you always wanted to know about log-periodic power laws for bubble modeling but were afraid to ask. The European Journal of Finance 19, 366-39.

Hüsler, A., D. Sornette and C. H. Hommes, 2013. Super-exponential bubbles in lab experiments: evidence for anchoring over-optimistic expectations on price, Journal Economic Behavior and Organization 92, 304-316. 
Jiang, Z., Zhou, W.-X., Sornette, D., Woodard, R., Bastiaenseng, K., Cauwels, P. 2010. Bubble Diagnosis and Prediction of the 2005-2007 and 20082009 Chinese Stock Market Bubbles. Journal of Economic Behavior \& Organization 74, 149-162.

Johansen, A. 2003. Characterization of large price variations in financial markets. Physica A 324, 157-166.

Johansen, A., Sornette, D. 1998. Stock market crashes are outliers. European Physical Journal B 1, 141-143.

Johansen, A., Sornette, D. 1999a. Critical crashes. Risk 12, 91-94.

Johansen, A. and D. Sornette, 1999b. Financial "anti-bubbles": log-periodicity in Gold and Nikkei collapses, Int. J. Mod. Phys. C 10(4), 563-575.

Johansen, A., Sornette, D. 2000. Evaluation of the Quantitative Prediction of a Trend Reversal on the Japanese Stock Market in 1999. International Journal of Modern Physics C 11, 359-364.

Johansen, A. and D. Sornette, 2001/02. Large Stock Market Price Drawdowns Are Outliers, Journal of Risk 4(2), 69-110.

Johansen A., Sornette, D. 2010. Shocks, Crashes and Bubbles in Financial Markets. Brussels Economic Review (Cahiers economiques de Bruxelles) 53, 201-253.

Johansen, A., Ledoit, O., Sornette, D. 2000. Crashes as critical points. International Journal of Theoretical and Applied Finance 3, 219-255.

Johansen, A., Sornette, D., Ledoit, O. 1999. Predicting financial crashes using discrete scale invariance. Journal of Risk 1, 5-32.

Kovalenko, T. and D. Sornette, 2013. Dynamical Diagnosis and Solutions for Resilient Natural and Social Systems, Planet@ Risk 1 (1), 7-33, Davos, Global Risk Forum (GRF).

Leiss, M., H.H. Nax and D. Sornette, 2015. Super-Exponential Growth Expectations and the Global Financial Crisis, Journal of Economic Dynamics and Control 55, 1-13.

Lera, S. and D. Sornette, 2015. Secular bipolar growth rate of the real US GDP per capita: implications for understanding past and future economic growth, ETH Zurich preprint (http://ssrn.com/abstract=2703882)

Lin, L., Sornette, D. 2013. Diagnostics of Rational Expectation Financial Bubbles with Stochastic Mean-Reverting Termination Times. The European Journal of Finance 19, 344-365. 
Lin, L., Ren, R., Sornette, D. 2014. The Volatility-Confined LPPL Model: A Consistent Model of 'Explosive' Financial Bubbles With Mean-Reversing Residuals, International Review of Financial Analysis 33, 210-225.

Lubetkin, M.J. 2006. Jay Cooke's Gamble: The Northern Pacific Railroad, the Sioux, and the Panic of 1873, Norman: University of Oklahoma Press.

Phillips, P.C.B., Shi, S-P., and Yu, J. (2015). Testing for Multiple Bubbles: Historical Episodes of Exuberance and Collapse in the S\&P 500, International Economic Review, 2015, 56 (4 ), 1043-1078.

Rousseau, P. L. 2002. Jacksonian Monetary Policy, Specie Flows, and The Panic of 1837. The Journal of Economic History 62, 457-488.

Seyrich, M. and D. Sornette, 2016. Micro-foundation using percolation theory of the finite-time singular behavior of the crash hazard rate in a class of rational expectation bubbles, Int. J. Mod. Phys. C (submitted 28 Jan. 2016) (http://ssrn.com/abstract=2722383)

Sornette, D. 1998a. Large Deviations and Portfolio Optimization. Physica A 256, 251-283.

Sornette, D. 1998b. Discrete scale invariance and complex dimensions, Physics Reports 297, Issue 5, 239-270 (extended version at http://xxx.lanl.gov/abs/cond-mat/9707012)

Sornette, D. 2003a. Critical Market Crashes. Physics Reports 378, 1-98.

Sornette, D. 2003b. Why Stock Markets Crash (Critical Events in Complex Financial Systems). Princeton: Princeton University Press.

Sornette, D. and P. Cauwels, 2014. 1980-2008: The Illusion of the Perpetual Money Machine and what it bodes for the future, Risks 2, 103-131.

Sornette, D. and P. Cauwels, 2015. Managing risks in a creepy world, Journal of Risk Management in Financial Institutions (JRMFI) 8 (1), 83-108.

Sornette, D., G. Demos, Q. Zhang, P. Cauwels, V. Filimonov and Q.Zhang, 2015. Real-time prediction and post-mortem analysis of the Shanghai 2015 stock market bubble and crash, Journal of Investment Strategies 4 (4), 77-95 (2015).

Sornette, D., Johansen, A. 1997. Large Financial Crashes. Physica A 245, 411422.

Sornette, D., Johansen, A. 1998. A Hierarchical Model of Financial Crashes. Physica A 261, 581-598. 
Sornette, D., Johansen, A. 2001. Significance of log-periodic precursors to financial crashes. Quantitative Finance 1, 452-471.

Sornette, D., Johansen, A., Bouchaud, J.P. 1996. Stock Market Crashes, Precursors and Replicas. J. Phys. I France 6, 167-175.

Sornette, D., Woodard, R., Zhou, W.-X. 2009. The 2006-2008 Oil Bubble: Evidence of Speculation, and Prediction. Physica A 388, 1571-1576.

Sornette, D., Woodard, R., Yan, W., Zhou, W.-X. 2013. Clarifications to Questions and Criticisms on the Johansen-Ledoit-Sornette bubble Model, Physica A 392, 4417-4428.

Sornette, D., Zhou, W.-X. 2006. Predictability of Large Future Changes in Major Financial Indices. International Journal of Forecasting 22, 153168.

Temin, P., 1989. Lessons from the Great Depression. Cambridge, Mass.: MIT Press.

Watanabe, K., Takayasu, H., Takayasu M. 2007a. Extracting the Exponential Behaviors in the Market Data. Physica A 382, 336-39.

Watanabe, K., Takayasu, H. , Takayasu M. 2007b. A Mathematical Definition of the Financial Bubbles and Crashes. Physica A. 383, 120-24.

Yan, W., Rebib, R., Woodard, R., Sornette, D. 2012. Detection of Crashes and Rebounds in Major Equity Markets. International Journal Portfolio Analysis and Management 1, 59-79.

Zhang, Q., Q. Zhang and D. Sornette, 2015. Early warning signals of financial crises with multi-scale quantile regressions of Log-Periodic Power Law Singularities, Int. J. Forecasting (submitted 14 Oct. 2015) (http://ssrn.com/abstract=2674128)

Zhou, W.-X., Sornette, D. 2002. Statistical Significance of Periodicity and LogPeriodicity with Heavy-Tailed Correlated Noise. Int. J. Mod. Phys. C 13, 137-170.

Zhou, W.-X., Sornette, D. 2003. Renormalization group analysis of the 20002002 anti-bubble in the US S\&P 500 index: Explanation of the hierarchy of five crashes and prediction. Physica A 330, 584-604

Zhou, W.-X. and D. Sornette, 2004. Antibubble and Prediction of China's stock market and Real-Estate, Physica A, 337 (1-2), 243-268.

Zhou, W.-X. and D. Sornette, 2005. Testing the Stability of the 2000-2003 US Stock Market "Antibubble”, Physica A 348, 428-452.. 


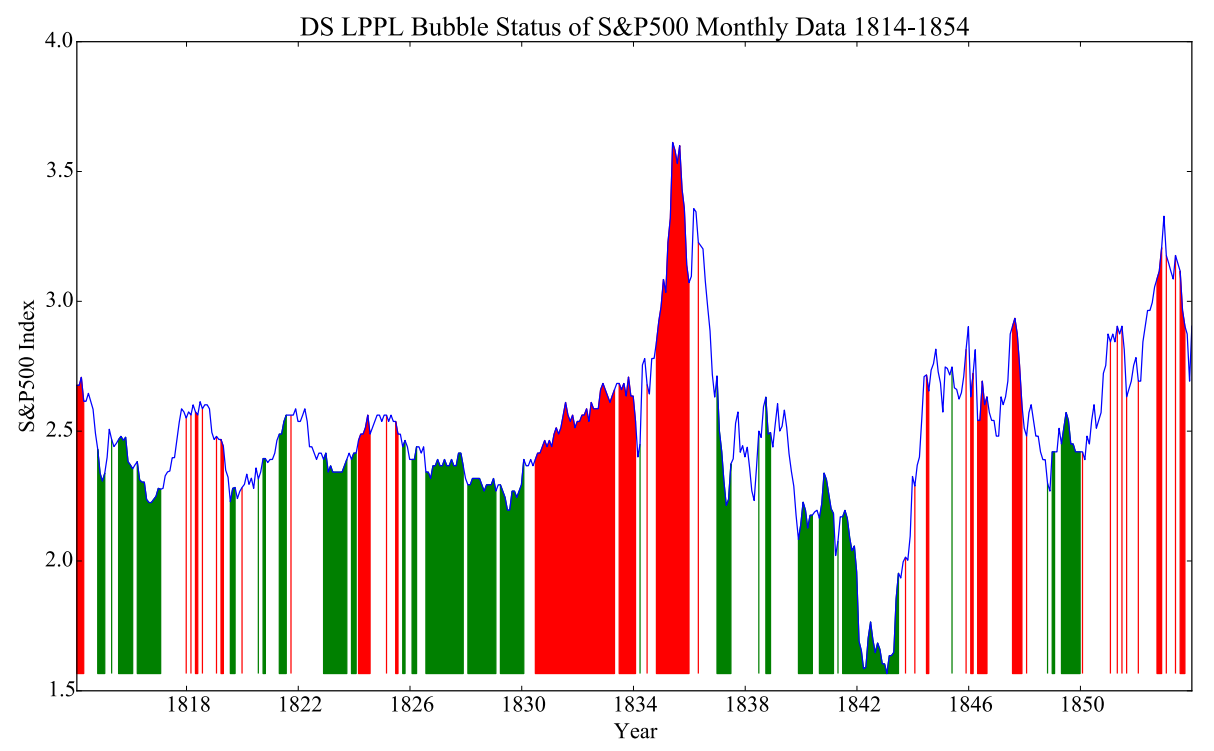

Figure 1: DS LPPLS Bubble Status of S\&P500 Monthly Data 1814-1854

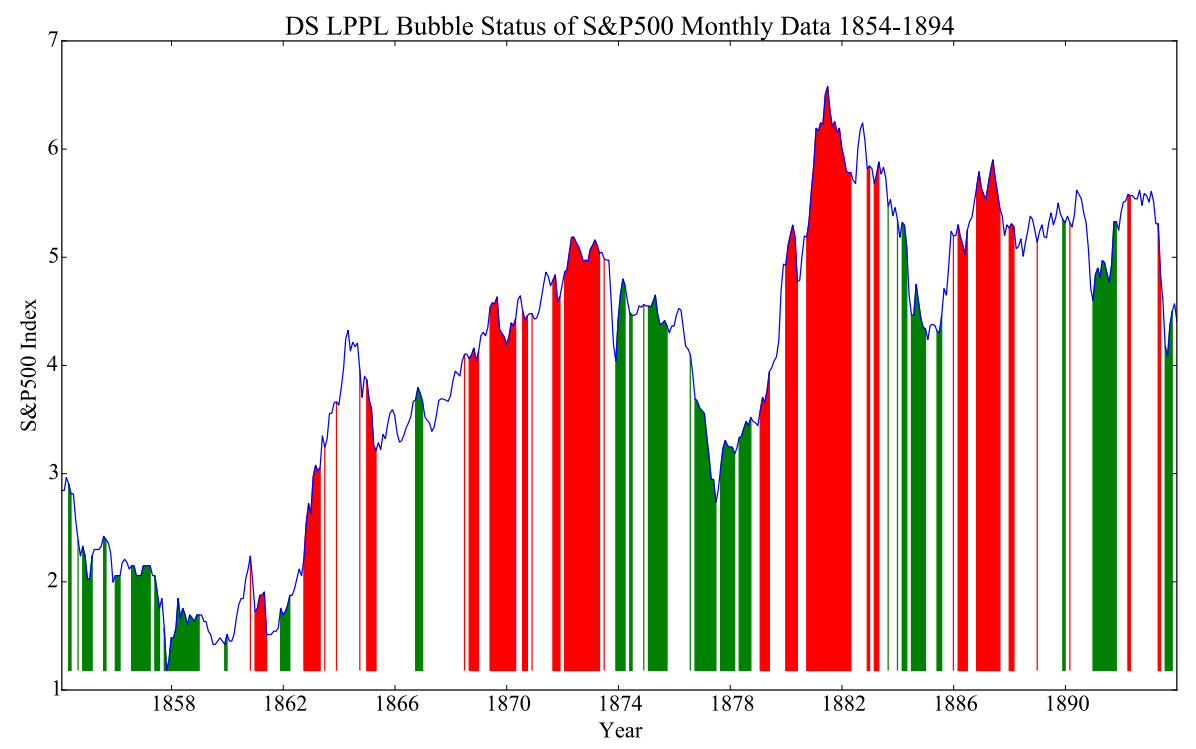

Figure 2: DS LPPLS Bubble Status of S\&P500 Monthly Data 1854-1894 


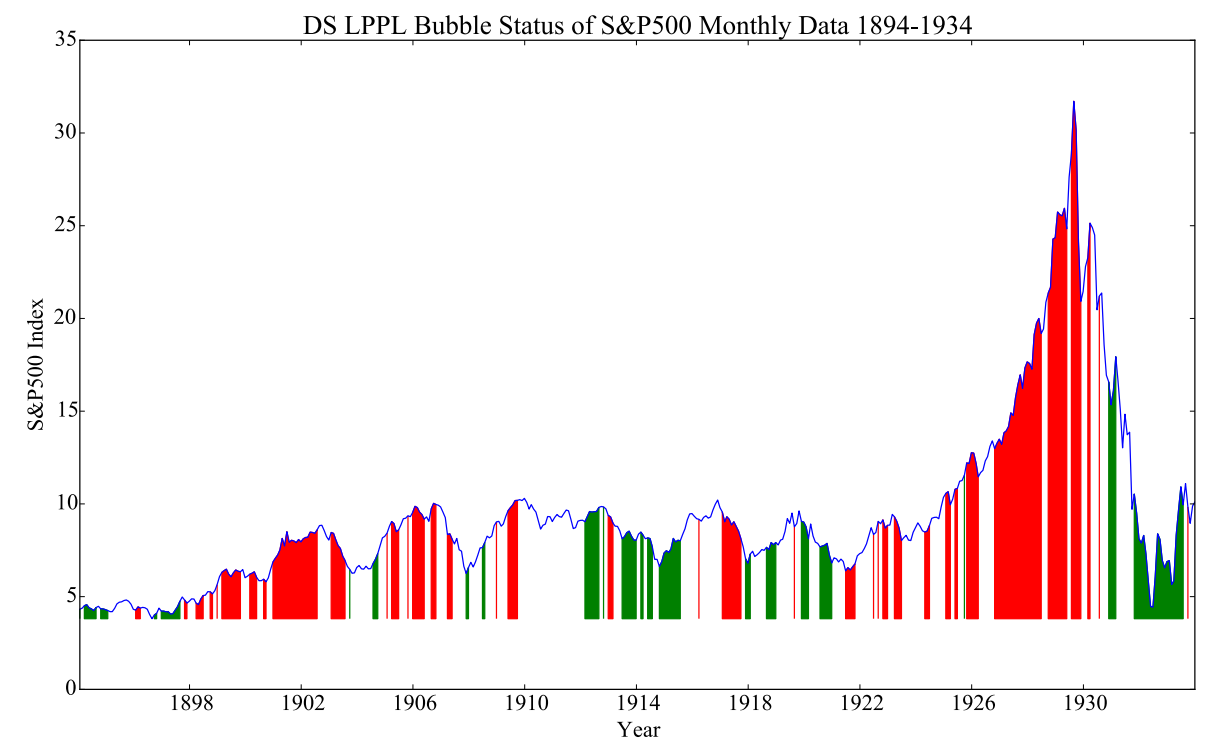

Figure 3: DS LPPLS Bubble Status of S\&P500 Monthly Data 1894-1934

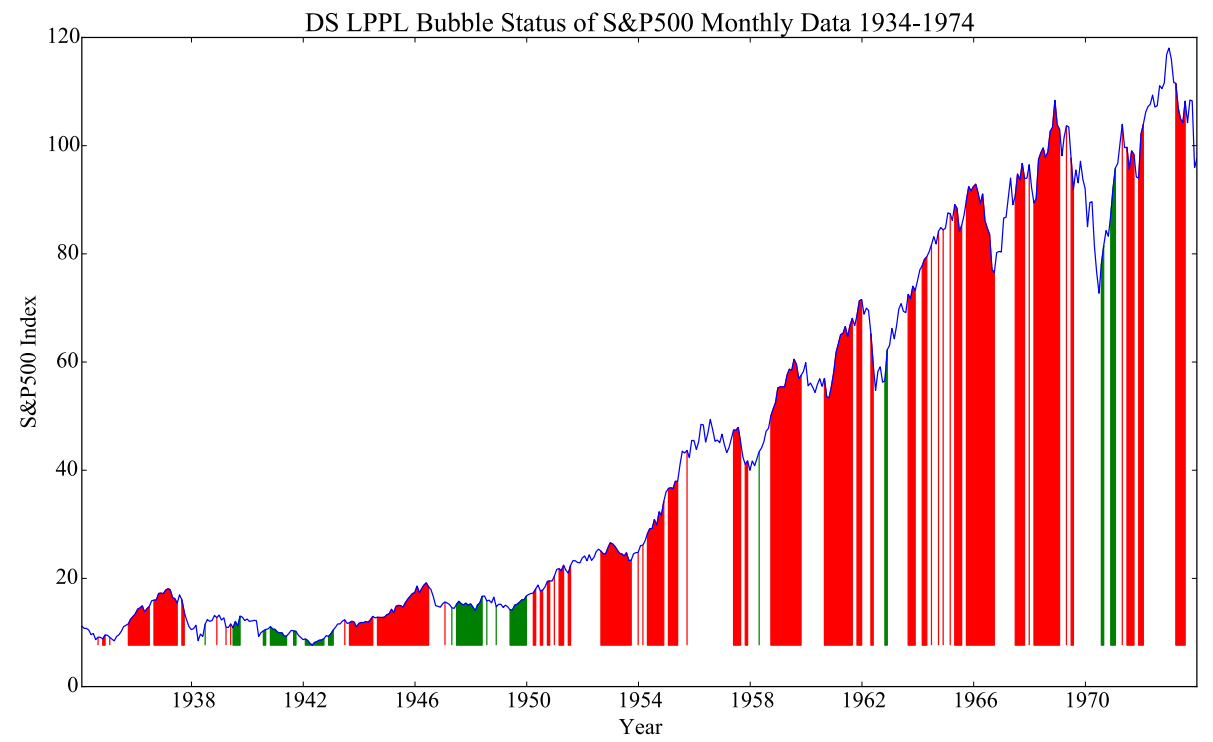

Figure 4: DS LPPLS Bubble Status of S\&P500 Monthly Data 1934-1974 


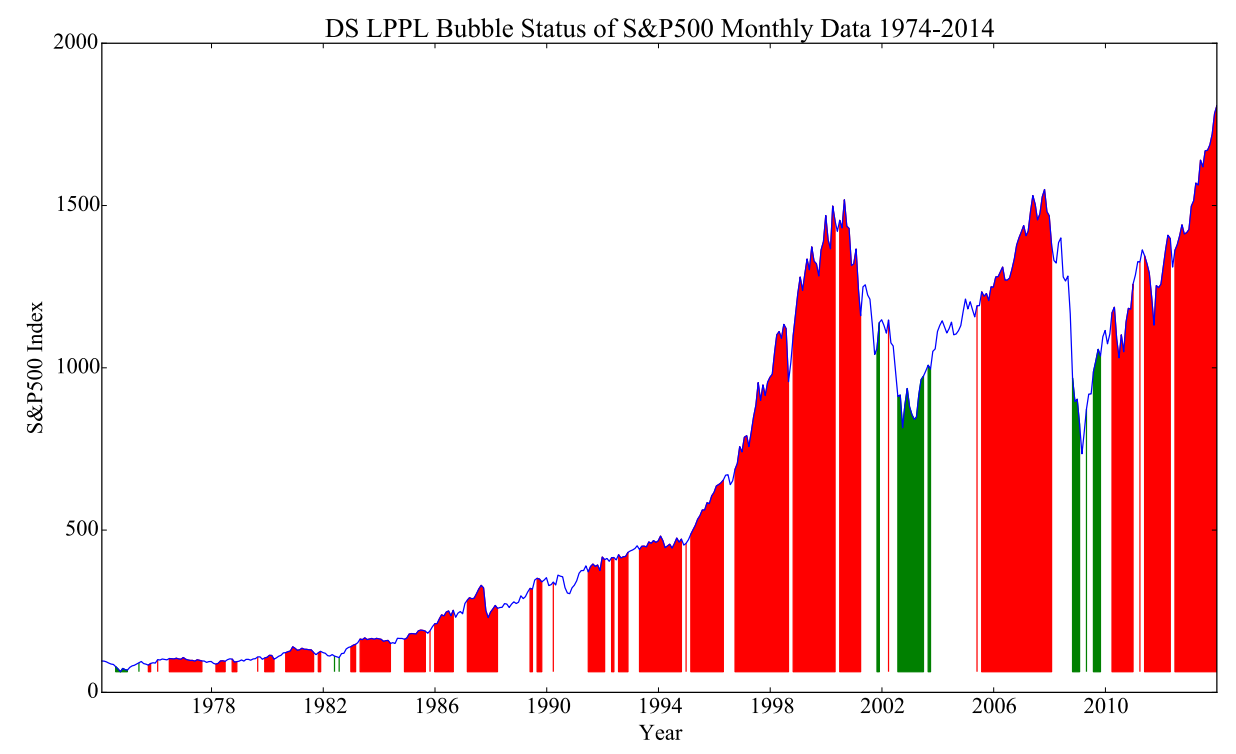

Figure 5: DS LPPLS Bubble Status of S\&P500 Monthly Data 1974-2014
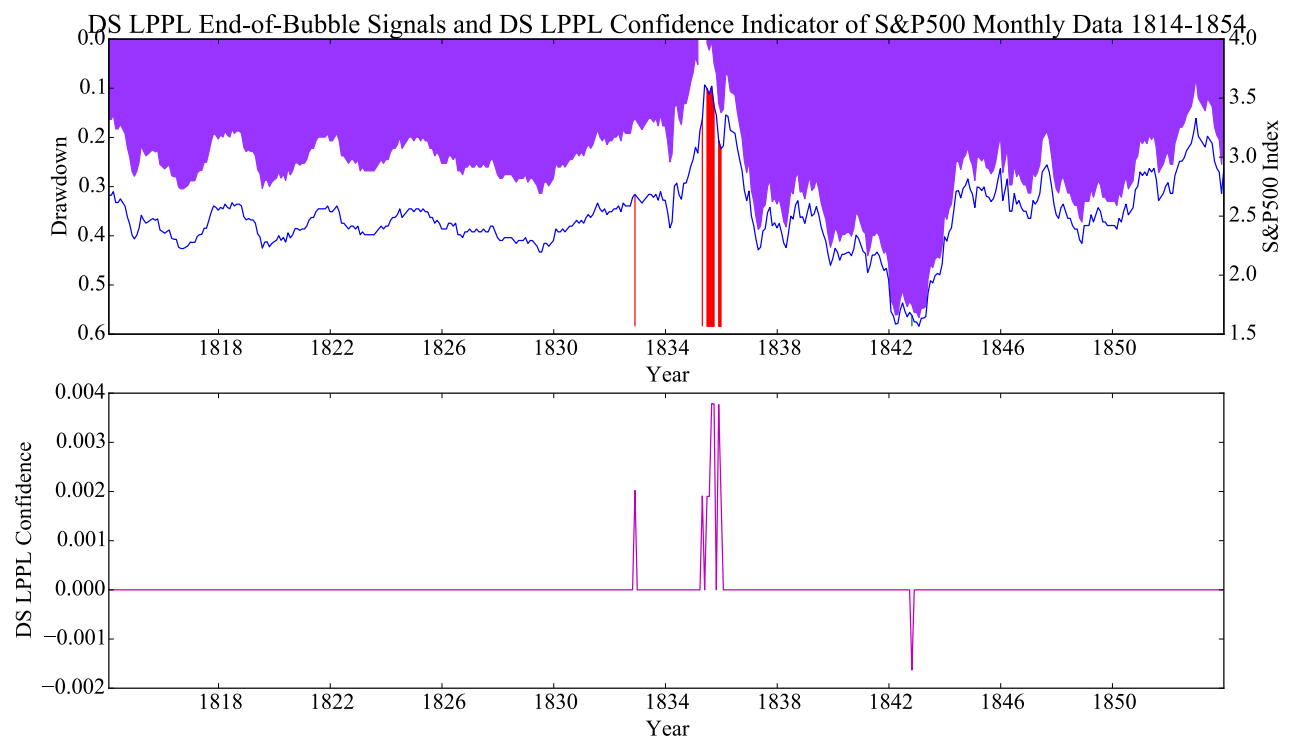

Figure 6: DS LPPLS End-of-Bubble Signals and DS LPPLS Confidence Indicator of S\&P500 Monthly Data 1814-1854 

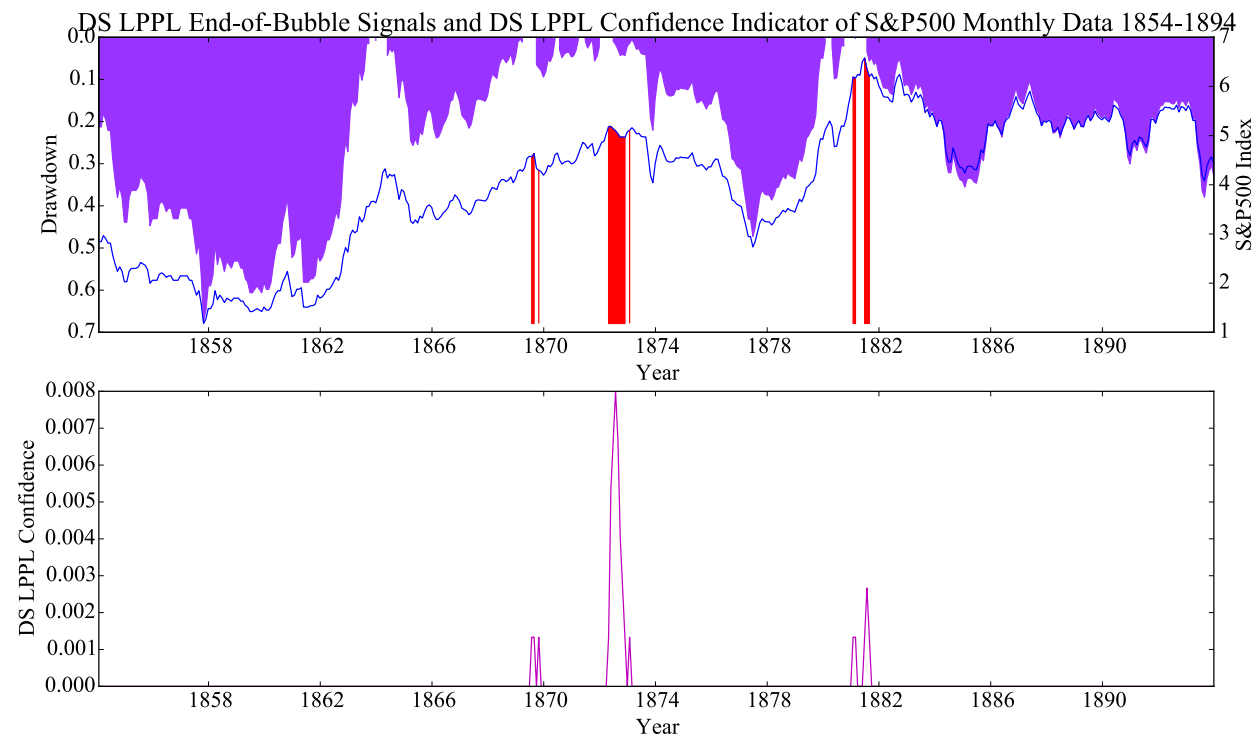

Figure 7: DS LPPLS End-of-Bubble Signals and DS LPPLS Confidence Indicator of S\&P500 Monthly Data 1854-1894
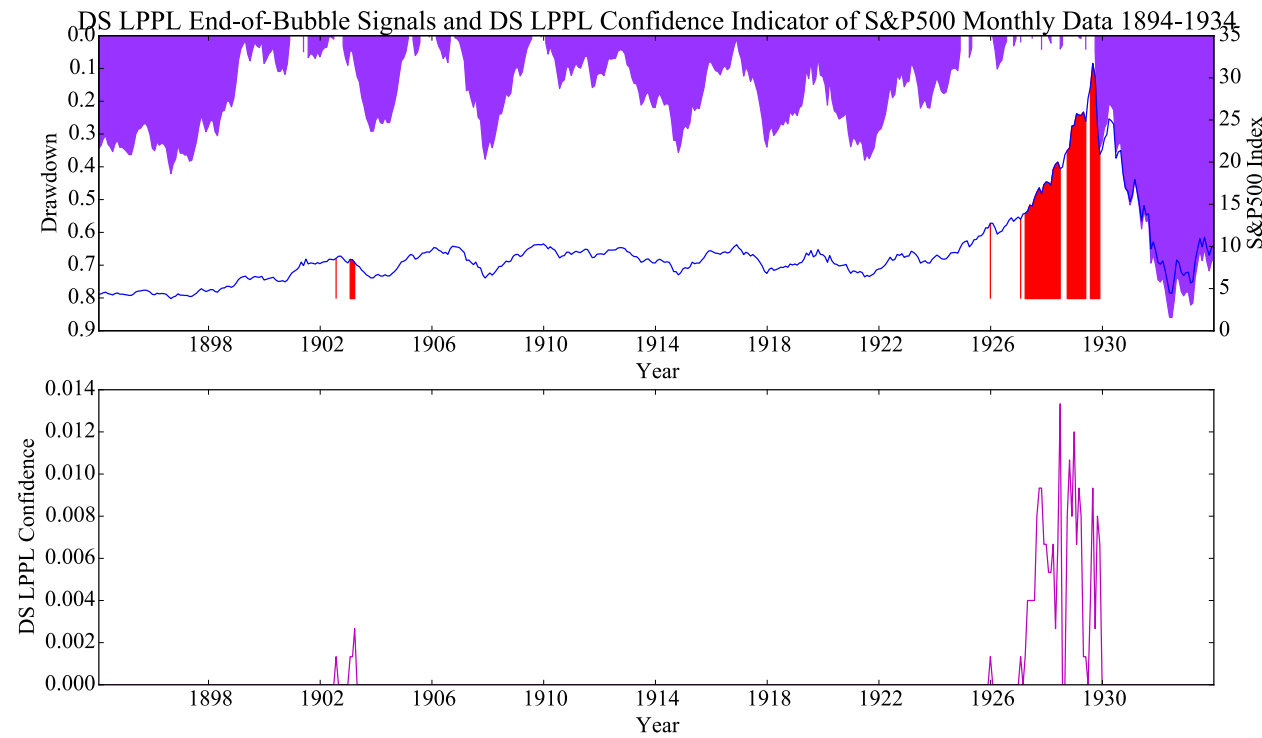

Figure 8: DS LPPLS End-of-Bubble Signals and DS LPPLS Confidence Indicator of S\&P500 Monthly Data $1894-1934$ 

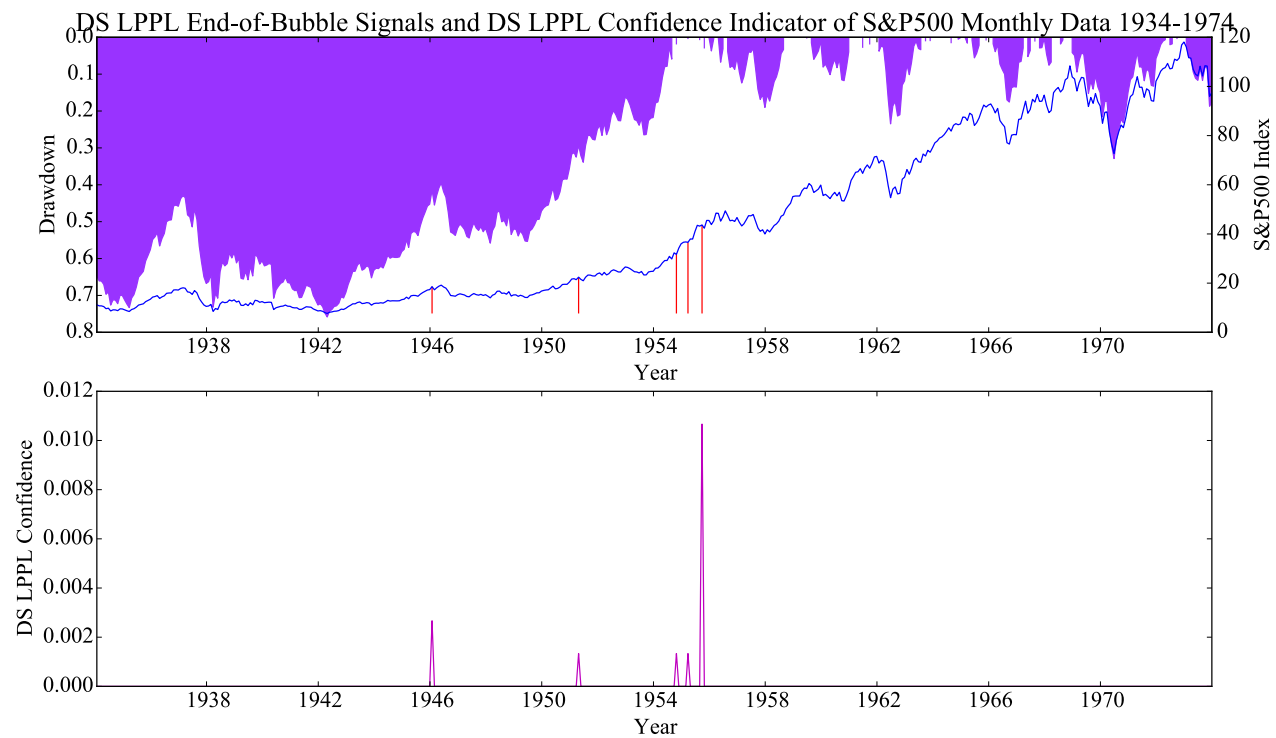

Figure 9: DS LPPLS End-of-Bubble Signals and DS LPPLS Confidence Indicator of S\&P500 Monthly Data 1934-1974
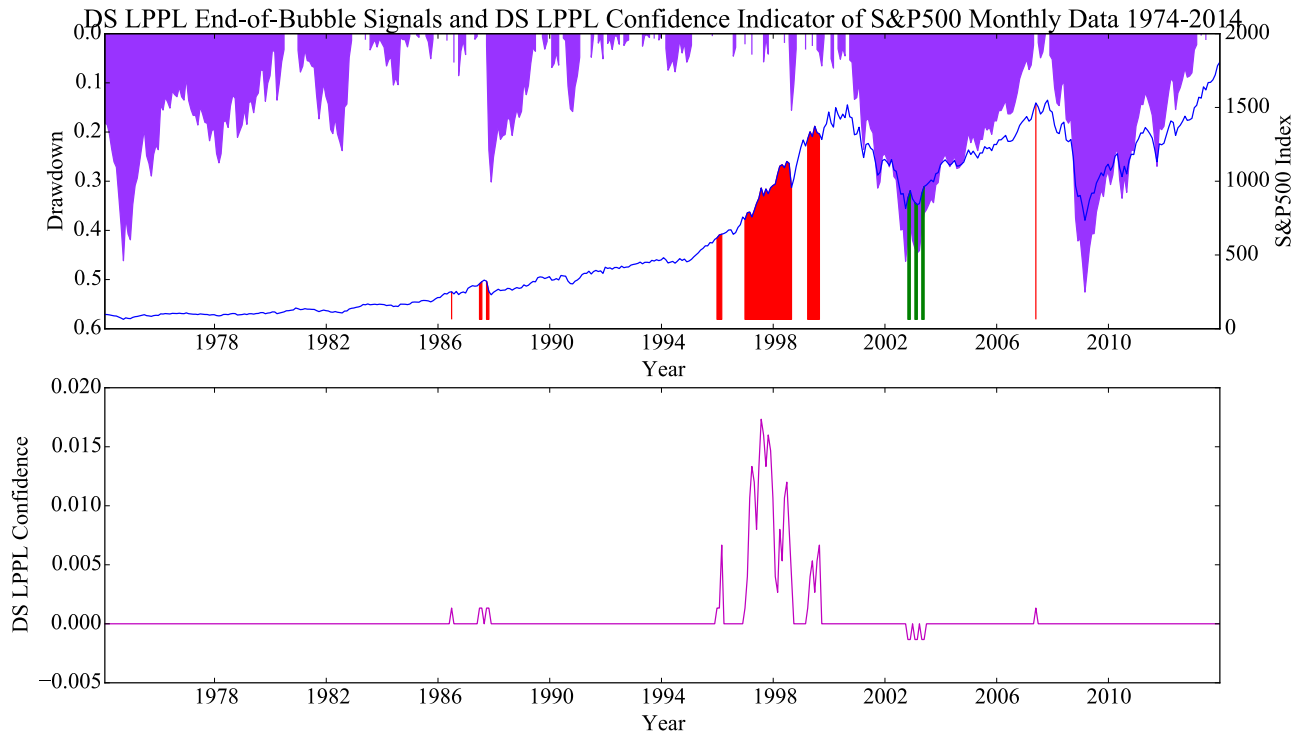

Figure 10: DS LPPLS End-of-Bubble Signals and DS LPPLS Confidence Indicator of S\&P500 Monthly Data 1974-2014 